\title{
LEADERSHIP IN COMMUNITY PARTNERSHIPS: SOUTH AFRICAN STUDY AND EXPERIENCE
}

\author{
Walid El Ansari \\ Faculty of Applied Sciences, University of Gloucestershire, Gloucester, United Kingdom
}

\section{SUMMARY}

Aims: This study examined the influence of leadership in multi-stakeholder partnerships. Four W.K. Kellogg-funded community partnerships in South Africa were evaluated. Participants included community, academic and health service partners. The partnerships aimed to achieve interprofessional community-sensitive health professions education.

Methods: We undertook: 1) quantitative assessment (survey, $\mathrm{N}=529$ ) of whether leadership skills were systematically associated with three partnership factors (satisfaction, sense of ownership and commitment); and the individual contributions of these factors to the partnerships' outcomes; and 2) qualitative assessment (semi structured interviews, $\mathrm{N}=46$ ) of the extent of coalition members' ratings of their leadership, the likelihood of concerns about their leaders; and the nature of these concerns.

Results: Quantitatively, partner's positive ratings of their leadership were consistently and significantly attended by better sense of ownership, commitment to and satisfaction with the partnerships. Variance in partnership outcomes was accounted for by leadership skills (26\%), ownership $(21 \%)$, commitment (20\%) and satisfaction (11\%). Partnership members who rated their leadership highly expressed fewer concerns (qualitatively) about their leaders. These concerns were: leadership visibility, openness and legitimacy; leadership features, styles and characteristics; the consequences of lack of appropriate leadership; and management procedures that were lacking.

Conclusions: Coalition efforts would benefit from focusing on factors that are conducive to effective leadership.

Key words: interprofessional education, leadership, community-based, partnership outcomes, mixed method evaluation

Address for correspondence: Walid El Ansari, Faculty of Applied Sciences, University of Gloucestershire, Oxstalls Campus, Oxstalls Lane, Gloucester, Gloucestershire GL2 9HW, United Kingdom. E-mail: walidansari@glos.ac.uk

\section{INTRODUCTION}

The need to provide more joined services in health and social care is now recognized by governments as a major objective, and inter-agency collaboration is a key theme in current UK government policy $(1,2)$. The realisation of inter-agency approaches frequently builds on the involvement of many professions and multiple stakeholders: training institutions, health services, community organizations, service users and others $(3,4)$. Such initiatives frequently take the form of partnerships that address community health needs and lay the basis for long term health planning (5). Indeed collaborations among health professions and other partners assist in engaging all stakeholders in a socially accountable manner as the foundation of healthcare education and practice (6). Unsurprisingly, in building empowering interprofessional efforts, partnerships have become a central plank in health and social care, and university-community partnerships have been employed for their combined synergy (7).

Partnerships are collective actions by individuals or organizations for a shared communal benefit greater than each could accomplish as an individual player (8). They combine the assets and skills of 'professionals', community and other stakeholders (9). There is consensus that the success of interprofessional initiatives depends on the leadership's commitment, where an essential pillar in partnership working is the skills of the partnership's leadership (10-12).
Partnership leaders engage constituencies, committees, taskforces, trustees, steering groups, and facilitators in coordinated policy, service delivery, research and evaluation for communitywide change. Leaders set agendas, facilitate meetings, and organize structures, procedures and processes in order to accomplish goals in a context where stakeholders participate voluntarily with little formal accountability (13). Leaders also negotiate options, delegate responsibilities, garner resources, solve problems, resolve conflict, promote equal status, encourage member collaboration and obtain support for coalition issues (14). At each stage of partnership development (formation, implementation, maintenance, institutionalization), skilful leaders enhance coalition functions and accomplishments, and lead the progression to the next stage (15).

This range of partnership stages, activities and stakeholders confirmed that a critical challenge to successful partnerships is effective leadership skills $(16,17)$. However, there is a lack of understanding of the influence of leadership in partnerships as well as the systematic study of its association with the attainment of partnership outcomes $(18,19)$. The purpose of the study described in this paper was to assess the relationships between the skills of the partnerships' leaders and partnership outcomes on the one hand, and three process measures exploring satisfaction, ownership and commitment on the other. We focus particularly on these three (organizational climate) process factors because of their two-fold relationships: to leadership skills; and to partnership outcomes. 
As regards to their relationships to leadership skills: leaders' management styles and communication are critical for member satisfaction and commitment; partnerships that value their leaders have satisfied members who exhibit greater ownership; and leader competence influences member satisfaction, and both affect member perceptions of leader competence/commitment (18, 20, 21).

In relation to their importance to partnership outcomes: member satisfaction, commitment, and expectations about outcomes are related to active involvement; satisfaction is correlated to increased organizational viability; cohesive organizations have satisfied members; durable coalitions have members with strong commitment; stakeholders with different commitment levels exhibit varied investments of time, effort and resources; and as member commitment develops, the scope and effectiveness of partnership activities is increased (22-24).

\section{THE INTERVENTION: SOUTH AFRICAN COMMU- NITY PARTNERSHIPS}

In the mid 1990s, WK Kellogg Foundation funded community partnerships for health professions education, aimed at midsize communities in South African provinces (35,000-300,000 residents). These localities had limited health/primary care infrastructure, lack of basic amenities, increased demand for services due to population influxes, and policies excluded 'black' students from universities. Health students were trained in hospitals and had little experience of inter-professional education and of primary services that met people's total health care needs. The partnerships participating in this study were located in such underserved and underprivileged areas.

Faced with such challenges, the South African partnerships were transforming health professions education. The premise was inter-professional education and the training of health professionals who were responsive and accountable to their communities (25). The partnerships linked national health professions education to district health systems policy and planning. Board of trustees and committees were set up at each partnership to support the efforts. Dialogues were initiated between community members, medical and nursing academics, civic agencies, health professionals, neighbourhood and business leaders, non-governmental organizations, teachers, faith communities, and women's, crèche and youth groups. The partnerships built governance structures, task forces, development projects, community consortia, and programmes within community-based primary health care sites (25).

These partnership efforts focussed on preparing health professionals for community-based primary care practice. They aimed at: creating a mutual investment between communities and future health professionals through joint community service projects; strengthening the process by which community agencies and constituencies become part of the decision making for education, research and services; developing multi-disciplinary teams to provide health care in the community; conducting communitybased research that explores the communities' concerns; and influencing the policy for the long term sustainability of health professions education in primary, community-based care. Hence, new academic-community primary care centres were initiated, where service, teaching and community development were conjointly amalgamated. In this context, students were provided with the opportunities to develop the skills, behaviours and attitudes needed for consequent joint working (26).

Such partnerships for education and social accountability were new concepts, so all partners needed development. New roles were undertaken by each of the three stakeholder groups. The academic partners now delivered some of their teaching for their health professions students in a multi-disciplinary fashion at the academic-community primary care centres; the health service partners contributed to the teaching of these students and brought a service perspective to the educational process; and within these previously disadvantaged localities, community involvement served to bring real life examples to the students that highlighted the interlacing relationships between health and social issues, thus changing the focus of health professions education from a diseaseoriented perspective to a health-oriented one. In the USA, similar Kellogg initiatives reported an increase of medical students who selected primary care residency training, while $54 \%$ of nursing students and $73 \%$ of the public and allied health students secured employment in rural or underserved communities (27).

\section{AIM OF THE STUDY}

The current analysis forms part of a wider study of community partnerships in South Africa (28). The five specific objectives were to:

- describe the context, aims and outcomes of four partnerships;

- compute each respondent's level of agreement on 11 dichotomous ('Yes/No') questionnaire items of leadership skills in the partnerships, use it to create a continuous Leadership Skills Score (LSS) for each partnership, and explore differences in LSS across four partnerships;

- assess whether higher LSS was associated with more positive ratings of three partnership process factors: satisfaction, ownership and commitment;

- measure individual contributions of LSS, satisfaction, ownership and commitment in explaining the variance in outcomes; and explore whether LSS per se influenced outcomes to different extents in partnerships with differing LSS levels; and, - assess whether higher LSS levels were associated with less qualitative concerns expressed by interviewees as regards the partnerships' leadership; and explore the themes.

\section{CONCEPTUAL FRAMEWORK}

In understanding how leadership relates to partnership functioning, Kumpfer et al. (18) proposed a model where leadership was related to team efficacy, satisfaction and outcomes. This paper's framework builds on Kumpfer et al. (18). Premised on extant literature, four sets of leadership skills: communication; collaborative style; involvement competencies; and social/educational capacity building abilities are critical for partnership leaders (Fig. 1). Indeed, leaders' interpersonal communication helps to achieve objectives and action $(29,30)$. Leaders facilitate members' collaborative engagement and decision-making, and build consensus, provide credit, seek views, and encourage involvement $(31,32)$. They also provide members with development opportunities, where stakeholder interactions with partners, staff or policy/ 


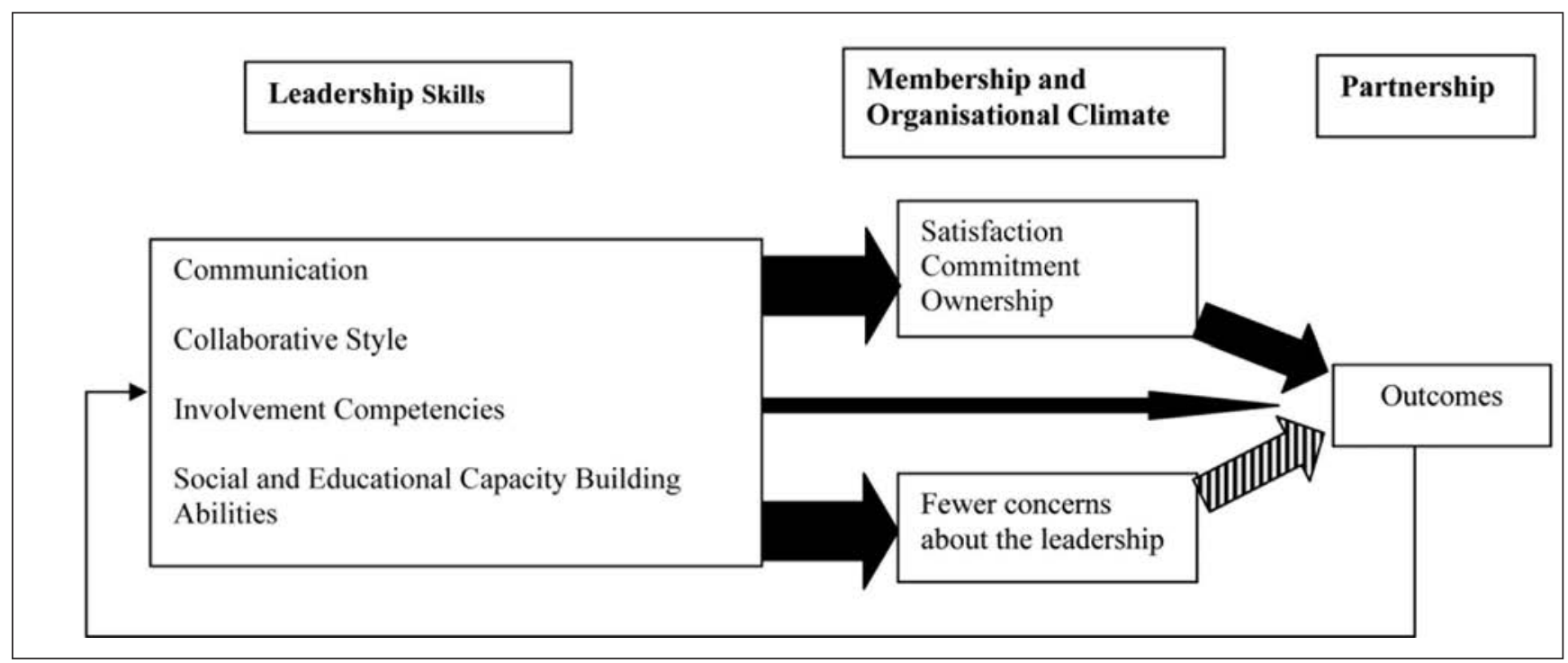

Fig. 1. Conceptual Model*.

* Derived from Kumpfer et al. (18), and expanded upon; the relationship that the stripped arrow represents was not formally tested.

engagement experts enhance the partnership's capacities (33). In addition, leaders facilitate community assets and expertise, and the skills that are developed result in advancement of members' knowledge (34).

The model also assessed three partnership process factors (satisfaction, ownership and commitment) proposing that as leadership skills increase, the organizational climate is enhanced across these factors. 'Organizational climate' variables are related to leadership skills and important to partnership outcomes (20). Collectively, highly rated leadership and an enhanced climate affect outcomes.

Finally, the model proposed that as leadership ratings increase, fewer concerns are articulated by members about leadership issues.

\section{METHODS}

The study was approved by the University of Wales, UK and consent was received from all the participating partnerships. Participation of the stakeholders in the survey and/or interviews was anonymous and voluntary, and respondents could withdraw from the study if they wished. Potential respondents were informed about the study aims; if partnership members wished to participate in the study, they provided verbal consent and were provided with a questionnaire to complete at their own pace. Data protection was observed at all times, and all the research material was securely stored.

This paper examined four (of seven) South African partnerships: one did not respond to invitations to participate in the study; another was examined in an earlier study; and a third partnership contributed quantitative but not qualitative data, so it was excluded from the current analysis. At each partnership, data collection started with members who: 1) were employed by the partnership; 2) sat on boards, committees, task forces, etc.; or 3) were included in the partnerships' 'register' of stakeholders. Once these 'active' participants were surveyed, they were asked about other person/s they met at partnership meetings. This 'snowballing' approach to building the sample had the benefit of identifying other 'less active' members at the 'fringes' of the partnerships, and difficult-to-reach potential respondents. The response rate of those who were identified as potential participants and consequently approached to complete a questionnaire was $\approx 90 \%$. Table 1 shows the size and composition of the whole sample and by partnership. Respondents comprised the partnerships' full-time staff charged with day-to-day activities (directors, researchers, programme managers, health service or educational coordinators/facilitators and administrators); health services personnel (managers, nurses, clinical instructors, superintendents, physiotherapists, and physicians at hospitals, clinics, municipality, or health/social administrations); and academics (nursing/medical faculty, tutors, lecturers, and instructors). The survey and interviews were informed by coalition theories that address membership, resources, support, processes, functions, and roles $(35,36)$. The research tools explored the partnerships' perceived internal, external, organizational, personnel features and outcomes.

\section{Quantitative Tool and Statistical Analysis}

Box I shows the partnership aspects under investigation. The questionnaire comprised published items (36-38). The eleven leadership items were selected from published questionnaires to reflect the breadth of partnership leadership skills (39). Before the study began, the partnerships' boards (in consultation with their constituencies) reviewed and agreed the questionnaire's language, acceptability and relevance to their outcomes. They indicated no need to translate the questionnaire into South African languages, as the survey's and membership's English literacy levels were appropriate. Then before the actual survey began, the questionnaire was piloted, and following feedback, minor amendments in the wording of a few items were undertaken.

Members who had attended partnership meeting/s were eligible to participate. The administration of the questionnaire comprised 3 phases: 1) the author met with the respondent and went through 


\section{Leadership skills: 11 items}

Communication

1. Provides me with a lot of good information

2. Reports our accomplishments through newsletters, etc. Collaborative Style

3. Makes me feel welcome at meetings

4. Gives praise/ recognition at meetings

5. Solicits my opinions and comments during meetings

Involvement Competencies

6. Asks me to assist with organizational tasks

7. Intentionally seeks out and welcomes my views

8. Intentionally seeks out the views of other people outside

the Partnership

Social and Educational Capacity Building Abilities

9. Provides me with continuing education opportunities

10. Holds social gatherings for Partnership members

11. Offers group activities (tours of other Partnerships, etc.) to Partnership members

\section{Sense of Ownership: 4 Items*}

1. I am committed to the work of the Partnership

2. I feel that I have a voice in what the Partnership decides

3. I feel a sense of pride in what the Partnership accomplishes

4. I really care about the future of this Partnership

\section{Commitment: 4 Items*}

1. Has your organization endorsed or adopted the mission and goals of the Partnership?

2. Does your organization participate in Partnership sponsored activities?

3. Has your organization publicly endorsed or cosponsored Partnership activities?

4. Does the community see the Partnership as a resource for influencing health personnel education?

\section{Satisfaction: 5 Items*}

1. I would not like to change anything about the Partnership

2. I am satisfied with how the Partnership operates

3. This Partnership is a worthwhile effort

4. The work accomplished by the Partnership has met my expectations

5. I am satisfied with what is accomplished by the Partnership

\section{Partnership Outcomes: 16 Items*}

HPE Impact Outcomes

1. Importance of the Partnership in the work undertaken to impact on Health Personnel Education in the targeted local health jurisdiction

2. That the Partnership efforts will influence Health Personnel Education

Curricula \& Services Outcomes - certainty that the Partnership will do what it has planned in relation to:

3. Transformation of curricula to be more community-based

4. Provision of primary care services

5. Increasing the use of multi-professional teams in providing health care

Student Outcomes - certainty that the Partnership will increase the numbers of:

6. Medical students who will enter primary health care practice

7. Nursing students who will enter primary health care practice

8. Other health professions students who will enter primary health care practice

9. Medical students who will choose to practice in underserved areas once they finish their training

10. Nursing students who will choose to practice in underserved areas once they finish their training

11. Other health professions students who will choose to practice in underserved areas once they finish their training

Community \& Policy Outcomes - certainty that the Partnership's activities:

12. Will increase community involvement in health care reforms

13. Will have influence on policy with respect to Health Personnel Education

Sustainability \& Structural Change Outcomes - certainty that:

14. The Partnership will continue as an identifiable organization

15. The Partnership will exist beyond Kellogg funding

16. One's organization is ready to implement structural changes to sustain the Partnership

Response scales - Leadership Skills (Yes/No); Satisfaction (1 = Strongly disagree/7 = Strongly agree); Commitment (1 = Not at all/7 = Very much); Ownership (1 = Strongly disagree/7 = Strongly agree); Outcomes ( 1 = Not at all certain/7 = Totally certain); *Higher ratings indicate more 'positive perception'; HPE - health personnel education; Items adapted from $(35,36,38,39)$.

the questionnaire explaining in detail the questions and instructions so that everything was absolutely clear to the respondent; 2) the questionnaire was then left with the respondent for the time that she/he felt was sufficient (usually a few days). Respondents were encouraged to leave blank any question/s that they could not answer, did not clearly understand or did not have the information for; and, 3) upon collection of the questionnaire, more light was shed on the question/s that were left unanswered. Respondents could then answer any of the unanswered items if they felt that they could comment and wished to do so. The completed questionnaires were then each given a unique code number and computer entered by the author whilst in the field. This anonymous and confidential nature of the survey, along with that respondents completed the questionnaires at any location they wished (at their home, at their place of work etc.) provided a 'safe space' for members to express their views, and circumvented any limitations of asking community partnerships members their opinions of their leaders/leadership.

Cronbach's alpha measured the internal consistency of multiitem scales. A quantitative LSS was computed for each respondent, based on percentage of 'Yes' ratings to 11 leadership items. Hence, the LSS ranged from $0-1$, where the closer it was to 1 (if a respondent rated all the leadership items 'Yes'), the better the person's views of their partnership's leadership. LSS was used to categorize the partnerships into descending levels of leadership skills. Independent samples t-tests/Analysis of Variance explored 
Table 1. Survey findings across four partnerships

\begin{tabular}{|c|c|c|c|c|c|}
\hline & $\begin{array}{l}\text { Whole } \\
\text { sample }\end{array}$ & $\begin{array}{c}\text { Partnership } \\
\text { A }\end{array}$ & $\begin{array}{c}\text { Partnership } \\
\text { B }\end{array}$ & $\begin{array}{l}\text { Partnership } \\
\text { C }\end{array}$ & $\begin{array}{c}\text { Partnership } \\
\text { D }\end{array}$ \\
\hline & $\mathrm{N}=529$ & $\mathrm{~N}=97$ & $\mathrm{~N}=105$ & $\mathrm{~N}=195$ & $\mathrm{~N}=132$ \\
\hline Leadership skills & & \multicolumn{2}{|c|}{ High LSS } & \multicolumn{2}{|c|}{ Low LSS } \\
\hline LSS mean (SD) & $70.52(24)$ & $80.6(19.7)$ & $79.3(20.3)$ & $65.5(22.8)$ & $63.4(26.6)$ \\
\hline \multicolumn{6}{|l|}{ Demographic characteristics } \\
\hline Age (years, mean) * & 39.7 & 40 & 41 & 40 & 38 \\
\hline Gender ( $\%$ females) & 64 & 75.3 & 62.9 & 78.5 & 42.4 \\
\hline Ethnicity (\% 'black') & 71.6 & 89.7 & 64.1 & 39.6 & 88.6 \\
\hline \multicolumn{6}{|l|}{ Work features } \\
\hline Present partnership experience (months) & 23.6 & 26.2 & 27.4 & 23 & 18.8 \\
\hline Past partnership experience (months) & 44.3 & 84 & 65 & 38.6 & 39.2 \\
\hline$\%$ of meetings attended in the past year & 55.4 & 70.7 & 55.6 & 58.5 & 38.9 \\
\hline \multicolumn{6}{|l|}{ Other partnership factors $* *$} \\
\hline Satisfaction (mean) & 4.56 & 4.93 & 5.24 & 4.38 & 4.01 \\
\hline Ownership (mean) & 5.22 & 5.74 & 5.88 & 4.90 & 4.81 \\
\hline Commitment (mean) & 4.98 & 5.54 & 5.57 & 4.83 & 4.31 \\
\hline
\end{tabular}

LSS: Leadership Skills Score; SD: standard deviation; * Across the partnerships, differences in age were the only ones that were not significant $(p=0.32)$; differences in all other variables were significant $(p<0.001)$; Cell values depict sample means, ** higher scores indicate more positive perceptions.

disparities between the partnerships across 3 factors (satisfaction, commitment, ownership). Stepwise regression examined the contributions of partnership factors to explaining the variance in outcomes. SPSS16 was used, significance level was $p<0.05$.

\section{Qualitative Tool and Analysis}

Semi-structured, tape-recorded, one-to-one interviews were undertaken (46 academic, health service, community, and staff interviewees; $\approx 11,30$-minute interviews at each partnership). During data collection, the first author lived in the locality of each partnership for some months to: familiarize with members and socio-cultural context; participate in project visits/meetings; and strategically select 'information-rich' interviewees representing the different stakeholders and administrative levels. A topic guide led the direction of inquiry (40). The interview questions asked about respondents' concerns regarding the styles, features and behaviours of the leadership of the partnerships.

The author reviewed the audiotapes, transcribed data and analyzed the text using grounded theory. Text was read/re-read and leadership-relevant items were identified and indexed to headings and categories (validated in later readings). Initial coding produced provisional concepts, and codes were compared and clustered into categories, then matched for links (41). Analysis was staged: 1) data review; 2) data inclusion; 3) cluster formation; and 4) review, with sense making and finding representations (42). Leadership themes were backed by quotations for descriptive immediacy (43). The emerging themes were discussed within the research team, and the authenticity of the findings was checked with some of the interviewees. A robust audit trail ensured quotes were traceable to coded participants which allowed identification of their partnership, role and duration of involvement, but ensured confidentiality (44). This decision 'audit trail' was available, and an independent researcher reviewed the raw data and the corresponding emerging themes.

\section{RESULTS}

\section{Respondents}

The alpha values of the multi-item scales indicated excellent internal consistency: leadership skills (0.78), satisfaction (0.85), ownership (0.78), commitment (0.93), and outcomes (0.94). As mean LSS was different across the four partnerships $(\mathrm{p} \leq 0.001)$, the partnerships were arranged in descending LSS order, enabling their grouping into 'High' (partnerships A/B) and 'Low' (partnerships C/D) leadership categories (Table 1). Grouping of sites into categories using a criterion is common (45). The survey participants exhibited varied demographic and work features.

In partnerships with high LSS (partnerships A and B), members had participated in their current partnerships for longer durations, had more past partnership experience, and attended more partnership meetings than respondents from low LSS partnerships (C and D). Collectively, these findings provided validation that the LSS, that was employed to group the partnerships into 'High' and 'Low' leadership skills categories, was suitable, sensitive and operated in the appropriate direction when tested on 'extreme' groups with different durations of service in their current partnerships, different extents of past experience with other partnership efforts, and different levels of attendance at meetings.

Health service interviewees were managers, nurses, clinical instructors, superintendent, physiotherapist, and physicians at hospitals, clinics, municipality, or health/social administrations $[\mathrm{n}=11 ; 80 \%$ females; mean age 42.5 years $(30-55) ; 3$ years' participation (1-5 years)]. Academics comprised nursing/medical faculty, tutors, lecturers, and instructors $[\mathrm{n}=8$; females; mean age 42.5 years (29-57); 2.5 years' participation (1-4 years)]. Community members were: teacher, civil servant, programme/ board chairs, lawyer, factory worker, development workers, 
businessman, and church minister, either attending as civic representatives or on their own behalf $[\mathrm{n}=13 ; 25 \%$ females; mean age 43 years $(30-55) ; 2.5$ years' participation ( $1-5$ years)]. Staff were the partnerships' full-time employees charged with day-today activities: director, researcher, programme managers, health service or educational coordinators/facilitators and administrators $[\mathrm{n}=14 ; 80 \%$ females; mean age 35.5 years $(24-55) ; 2.5$ years' participation (1-4 years)].

\section{Partnerships}

Are Leadership Skills Consistently Associated with Three Partnership Process Factors?

Partnerships with 'High' leadership rated the three factors under study more favourably than 'Low' leadership partnerships. Positive feelings about their leaders were consistently and significantly attended by more satisfaction, sense of ownership and commitment.

What Contributes to Explaining the Variance in Outcomes?

Regression analysis showed that all four factors (leadership, ownership, commitment and satisfaction) were independently and positively associated with better outcomes (Table 2). Leadership skills positively contributed to explaining the variance in outcomes, followed by ownership, commitment, and satisfaction. The interaction between LSS and partnership exhibited no influence on outcomes ( $p=0.78$, data not shown), suggesting that LSS per se did not influence the outcomes to different extents in partnerships A and B (High LSS) than in partnerships C and D (Low LSS).

Are Partnerships with Higher Ratings of Their Leadership Less Likely to Have Concerns about Their Leaders?

The four themes that emerged from the interview data were: visibility, openness and legitimacy; leadership features, styles and characteristics; management procedures that were lacking; and consequences of lack of appropriate leadership. Figure 2 shows examples of the data structuring. The qualitative quotes were then mapped by partnership and by stakeholder, where Table 3 depicts the frequency and cause of the concerns about leadership. 'High' leadership sites (partnerships A/B) expressed less concerns about leadership than 'Low' leadership sites (partnerships C/D).

Table 2. Factors that account for variance in partnership outcomes

\begin{tabular}{|l|c|}
\hline Factor & Standardized $\boldsymbol{\beta}^{*}$ \\
\hline Partnership C & Reference \\
\hline Leadership skills & 0.261 \\
\hline Partnership B & 0.225 \\
\hline Ownership & 0.210 \\
\hline Commitment & 0.198 \\
\hline Partnership A & 0.196 \\
\hline Partnership D & 0.171 \\
\hline Satisfaction & 0.109 \\
\hline${ }^{*}$ All significant at $p<0.001$, except satisfaction $p=0.007$.
\end{tabular}

\section{Leadership Theme 3: Management Procedures that Were Lacking}

Being tri-partite coalitions, partners needed to share power, where devolution of responsibilities is one way of power sharing. However, such sharing seemed lacking: "management mostly by the director, what suits him, needs to have a deputy as he is always occupied". Similarly, consultation was lacking: "no consultation, decisions taken alone [by director]", and more mutual trust could have been beneficial: "director needs to trust the people she works with". Conversely, leaders also needed the support of their member constituencies in order to 


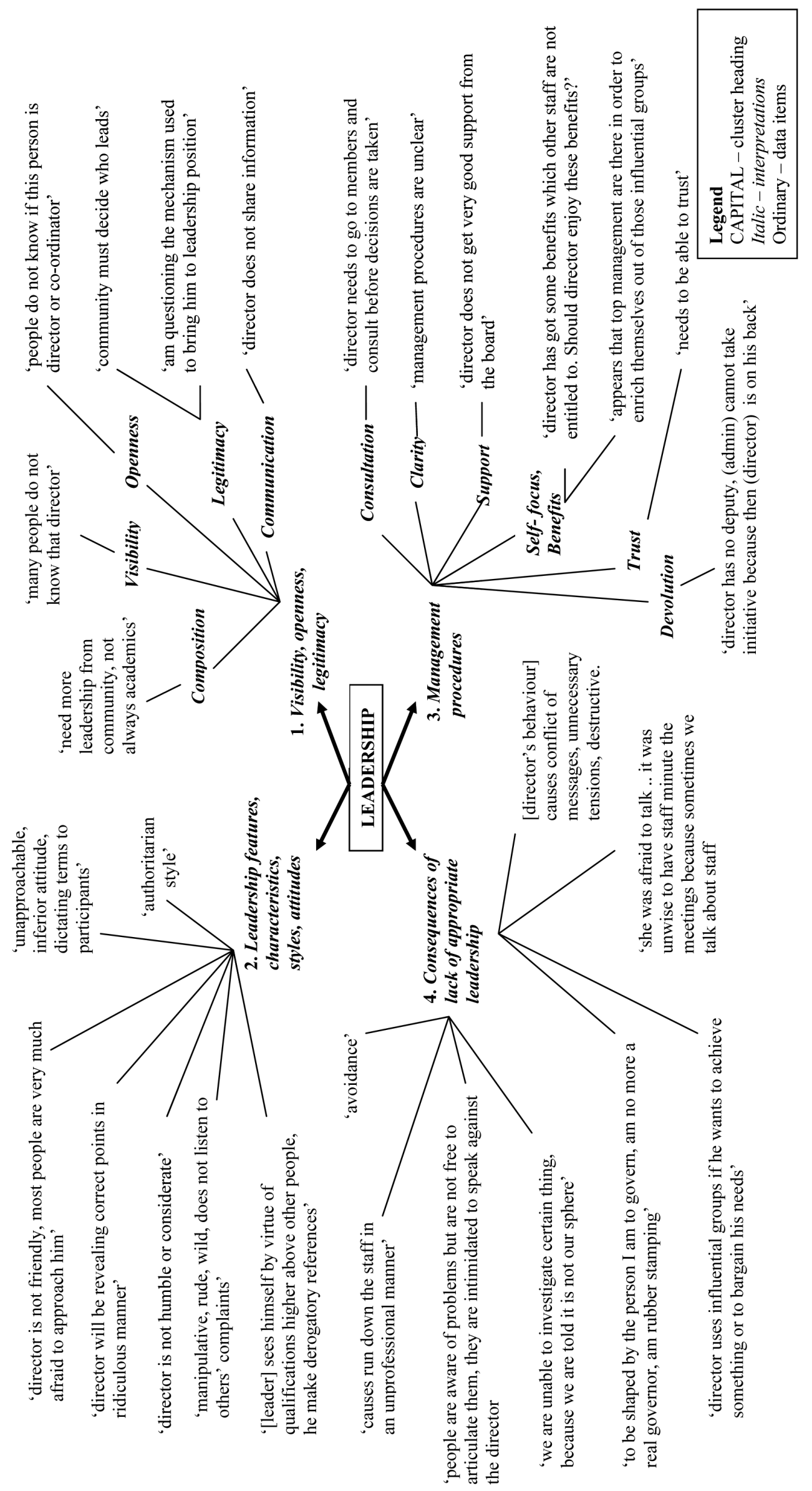

Fig. 2. Qualitative data structuring. 
Table 3. Interview findings of leadership concerns across four partnerships

\begin{tabular}{|c|c|c|c|c|}
\hline \multirow{2}{*}{ Concerns } & Partnership A & Partnership B & Partnership C & Partnership D \\
\hline & \multicolumn{2}{|c|}{ High leadership skills } & \multicolumn{2}{|c|}{ Low leadership skills } \\
\hline \multicolumn{5}{|l|}{ General* $^{*}$} \\
\hline Visibility & & & Health & Community \\
\hline Openness & & & & Community \\
\hline Attendance at meetings & & & Health & \\
\hline Composition of leadership & & & & Health \\
\hline Legitimacy & & & & Health \\
\hline Leaders imposed themselves & & & & Health \\
\hline Leaders impose decisions upon community & & & & Health \\
\hline Communication, providing information & & & Staff & Community $2 x$ \\
\hline Self development/self interest & & Staff & Staff & \\
\hline Rude to staff member/s & & & Staff & \\
\hline Occasional 'racist' concerns & & & Staff & \\
\hline Misuse of funds, power, other benefits & Community & & Staff & \\
\hline Only staff were paid overtime for late meetings & & & & Health \\
\hline \multicolumn{5}{|l|}{ Leadership features } \\
\hline Leadership characteristics & & Health & & Health \\
\hline Leadership styles/attitudes & Community & Health & Staff $2 x$ & Community/Health \\
\hline Attitude of the director & & & & Community \\
\hline Power tactics & & & & Health \\
\hline \multicolumn{5}{|l|}{ Management procedures: lacking } \\
\hline Clarity & & & & Health \\
\hline Consultation (generally or re-posts/buildings) & Community $2 x$ & & Staff & Health \\
\hline Support & & Health/Staff & Staff & \\
\hline Devolution (financial/other) & & Health/Staff & & \\
\hline \multicolumn{5}{|l|}{ Consequences of lack of appropriate leadership } \\
\hline Intimidation, avoidance, inhibition & Community $2 x$ & & & Staff \\
\hline Lack of involvement & Community & & & \\
\hline Conflict/tensions & & & Staff & \\
\hline \multicolumn{5}{|l|}{ Challenge } \\
\hline Lack of representation & & & & Community \\
\hline Use of influential (pressure) groups & & & & Health \\
\hline \multicolumn{5}{|l|}{ Board of trustees } \\
\hline Size & Community & & Staff & \\
\hline Composition & Community & & Staff $2 x$ & \\
\hline Meetings & & & Staff & \\
\hline Interaction & & & Staff & \\
\hline Communication & & & Community & \\
\hline Implementation & & & Community & \\
\hline
\end{tabular}

* Cells (intersect between concern and partnership) depict the stakeholder group expressing the concern (Health: health services; Community: community member/s; Staff: partnership's staff); $2 x$ indicates that the given concern was raised by two different members of the given stakeholder group for the given partnership.

undertake their work efficiently: "the director does not get support or direction from the board, she should be empowered to take firm decisions". Within their internal operations, these South African collaborative efforts required some accountability: "we need some control, the director controls the money". They reported that the benefits (across a spectrum of activities) were not equally accrued across the partners: "problem with attending the meetings, [staff] are paid overtime, we [health department] are not paid", "staff want to be in the same position to use the partnership's car or telephones". 


\section{Leadership Theme 4: Consequences of Lack of Ap- propriate Leadership}

By definition, coalitions are democratic structures. However, members were reticent to express their concerns: "because of fear of consequences from director, community does not want to put their complaints in writing". Stakeholders felt 'not free' in meetings: "director must not be present when we discuss issues because people are uncomfortable". The consequences were poor engagement: "people refuse to be involved, they observe certain issues but do not challenge it", and potential conflict: "this leads to conflict in the partnership". Conflict could be followed by questions of legitimacy: "as result of conflict, there is lack of recognizing her [director] as the partnership's leader", where coalition leaders then resort to other methods to achieve governance: "[director] used influential pressure groups (local women's league) in applying pressure and accomplishing the agenda".

\section{DISCUSSION}

This study employed a mixed method approach to assess the associations of effective leadership in partnership initiatives. Most studies of collaboration and inter-agency working only considered a narrow range of quantitative indicators, despite calls for adopting a broader approach that combines qualitative and quantitative research $(2,44)$. The analysis employed in this paper assessed the views of front-line practitioners and partnership members in addition to the experience of community people who use the services.

As regards to the first and second objectives of this study, this paper described the context, aims and outcomes of four interprofessional partnerships in South Africa (529 respondents) that aimed at increasing the numbers of health professions students who would select primary care training after their graduation, and who would choose to serve in rural or underserved communities. We computed each respondent's level of agreement on 11 questionnaire items of leadership skills in the partnerships, used it to create a continuous Leadership Skills Score for each partnership, and explored the differences in LSS across four partnerships, categorising them into partnerships with high (partnerships A and B) or low LSS partnerships (C and D).

In connection with objective three, higher LSS partnerships exhibited more member satisfaction, ownership and commitment. These quantitative findings suggested that leadership was consistently critical to partnership process factors, in agreement with others (21). However, we expanded on Kumpfer et al. (18): leadership not only related to satisfaction but also to greater sense of ownership and commitment (20). This triad (satisfaction, ownership, commitment) enhances organizational viability, cohesiveness and durability. They also increase the partnership's extent of activities and the effectiveness of implemented programmes, in addition to boosting members' time, effort and resource investments in the partnership (22). Indeed, at this historical time when South Africa was experiencing its first democracy after apartheid, members' satisfaction, sense of ownership and commitment were important elements in these inter-professional collaborative efforts.

In relation to objective four, leadership contributed positively and independently to the variance in outcomes, followed by ownership, commitment, and satisfaction. Effective leadership was associated with better outcomes, in agreement with others
$(16,17)$. However, whilst Kumpfer et al. (18) related leadership mainly to team efficacy, the current study employed 16 curricular/ student, services, community, policy, sustainability and structural change outcomes critical to such efforts (46). Such breadth of outcomes is vital for the South African lay communities who lacked appropriate health care facilities, services, personnel and policy, and is also critical when holistically assessing partnerships for health professions education reforms. The findings of the present study contributed to expanding the current models (18), particularly that the study's five areas of outcomes considered the extent to which: curricula were transformed; primary health care services were provided by teams; health professions students entered primary care practice; community engaged in health care reforms; and the partnerships continuing as identifiable organizations. Nevertheless, leadership skills did not influence outcomes to different extents in higher LSS partnerships than in low LSS partnerships.

As regards the fifth objective, the qualitative findings showed that higher LSS partnerships exhibited fewer concerns about the leadership. The qualitative findings complemented the survey by: (1) affirming that effective leaders not only influenced process and outcome factors of partnerships, but were simultaneously associated with fewer membership concerns; and (2) providing the wider picture and fine-grain day-to-day qualities that should receive attention by successful partnership leaders. We are not aware of mixed methods studies that examined such relationships.

The first leadership theme (visibility, openness and legitimacy) is in agreement with others. Collaborative leadership promotes trust, respect, and openness among members, and leaders need to be visible (45). Communication increases satisfaction, commitment, informs/empowers members, and fosters continuity; and networking is a valuable leadership skill (47). The findings of the current study also supported that the methods to select leaders were crucial for their legitimacy, and that leaders' credibility is critical (20).

Theme 2 (leadership features, characteristics, styles) supported that leaders' characteristics influence team outcomes. Indeed, collaborative leadership is engaging members in collective problem-solving (48). In partnerships, leadership is dispersed and 'community' is an equal partner to other 'professionals', where empowered lay people play active roles $(31,49)$. However, the findings of the current study suggested that more bridge-building/ shared leadership with the community was required, rather than some instances of 'divide and rule' or favouritism that some interviewees reported. Leaders' 'boundary spanning' promotes inter-group relations, supporting the current study findings that lateral rather than hierarchical relationships are suited to partnerships, where leaders influence members through relationship building $(50,51)$.

Theme 3 (partnership management procedures) is also in agreement with the literature. Devolution of responsibility as a power sharing action is important in managing a coalition (47). As consultative leaders report to the membership, hence they cannot lead by formal positional power, rendering the building of mutual trust vital, where trust provides the collaborative dynamic of a learning organization (52). The findings of the current study showed that more devolution, consultation and trust were beneficial for these efforts. Leaders face difficulties associated with their job, so better understanding of their roles (31) and supporting them 
are critical. Conversely, leaders need to be attentive to member's concerns, and as our findings suggested, this leaves no space for self-interests, and benefits need to be equitably accrued.

Theme 4 (consequences of lack of appropriate leadership) supported the published literature. Partnerships encourage members to talk openly in shaping the agenda (14). The findings of the current study depicted that inhibition restricts full/frank discussions and consequently the quality of decision-making. Leaders bring people together, supporting our findings that poor leadership is associated with lack of involvement of disappointed members, and that conflict is expected in coalitions, resulting in questioning the leaders' legitimacy (31). Facing this, managers can be manipulative in influencing agendas (31). Indeed leadership is "a skilful process of organizing, achieved through negotiation, to achieve acceptable influence over the issues within and between groups" (53). It has a creative dimension (helping people make sense of their social worlds), and a political dimension (valuing possible lines of action). 'Collaborative thuggery' or deliberate steps to influence the agenda have been described (31), supporting the findings of the current study that leaders sometimes could use influential groups to garner power.

Leading partnership efforts is not easy, and as effective governance does not occur spontaneously, efforts to study leadership through the evaluation process are important $(51,54)$. This paper has contributed to theory building of leadership in inter-professional partnerships. Quantitatively, it expanded on Kumpfer et al.'s (18) propositions that leadership is not only related to satisfaction but also to members' greater sense of ownership and commitment. Qualitatively it highlighted that realizing the partnership advantage requires attention to the many themes, as members' concerns hamper coalition advancement. Leaders' visibility, openness, composition, legitimacy, and communication are essential, and their styles and attitudes are closely viewed by members. A climate of trust, clarity, consultation, communication, and devolution confirms the partnerships' democratic nature.

This study has limitations. Survey data infer association between factors rather than cause. We examined four partnerships in one country, hence findings may not be fully generalizable to partnerships in other geographic, cultural, or socioeconomic settings, although the published literature suggests that lessons learnt from partnership initiatives are portable across countries and projects. Whilst the current analysis did not include partnership development stage, all partnerships were at the same stage of implementing their programmes. Interview analysis mapped the qualitative concerns, without assigning weights to length of quotes, leadership feature addressed, or respondent's duration of involvement. Conversely, the analysis used 11 leadership skills and 3 stakeholders on data from 4 partnerships. We are not aware of studies that combined quantitative and qualitative data to bear on leaders' influence on partnership factors as well as on the breadth of members' concerns. Future research should: (1) employ a wider range of leadership skills; (2) employ a wider range of process variables; (3) relate specific leadership skills to particular processes or outcome factors; (4) precisely delineate the intermediate variables that intervene; (5) identify the types of assistance/training that best develops such skills; and (6) study these relationships using longitudinal design that would further inform the proposed framework, and allow the exploration of dispersed leadership/teamwork skills needed for partnerships.

\section{CONCLUSION}

Leadership skills are critical for the processes and outcomes of successful inter-professional partnerships than previously envisaged, hence they require attention. A range of collaborative skills needs to be noted at selection stages of the leaders for collaborative efforts. Coalition efforts would benefit to target and/or train leaders in styles that are conducive of effective leadership amidst inherent subterfuge, manipulation, or co-opting. Facilitative leadership styles will depend on organizational complexity and the mode of 'doing business', but supportive leadership behaviours are indeed associated with less member concerns. This could avert potential conflicts.

\section{Acknowledgement}

The author thanks the South African Community Partnerships that participated in this research; and the anonymous reviewers for their constructive comments which helped strengthen the paper.

\section{REFERENCES}

1. Gannon-Leary P, Baines S, Wilson R. Collaboration and partnership: a review and reflections on a national project to join up local services in England. J Interprof Care. 2006 Dec;20(6):665-74.

2. Glasby J, Dickinson H. Greater than the sum of our parts? Emerging lessons for UK health and social care. Int J Integr Care. 2008;8:e67.

3. El Ansari W, Phillips CJ. Interprofessional collaboration: a stakeholder approach to evaluation of voluntary participation in community partnerships. J Interprof Care. 2001 Nov;15(4):351-68.

4. Sitzia J, Cotterell P, Richardson A. Interprofessional collaboration with service users in the development of cancer services: the Cancer Partnership Project. J Interprof Care. 2006 Jan;20(1):60-74.

5. Anonson J, Leischner C, Manahan C, Randal J, Wejr R. Interdisciplinary collaborative approach to health education: a partnership addressing community health needs and laying the groundwork for long term planning in health education. J Interprof Care. 2008 Jan;22(1):107-9.

6. Ho K, Buote D, Jarvis-Selinger S, Lauscher HN, Ferdinands L, Parboosingh $\mathrm{J}$, et al. Achieving social accountability through interprofessional collaboration: the Canadian medical schools experience. J Interprof Care. 2008;22 Suppl 1:4-14.

7. Jarvis-Selinger S, Ho K, Lauscher HN, Liman Y, Stacy E, Woollard R, et al. Social accountability in action: University-community collaboration in the development of an interprofessional Aboriginal health elective. J Interprof Care. 2008;22 Suppl 1:61-72.

8. El Ansari W, Phillips CJ, Hammick M. Collaboration and partnerships: developing the evidence base. Health Soc Care Community. 2001;9(4):21527.

9. Clark NM, Doctor LJ, Friedman AR, Lachance LL, Houle CR, Geng X, et al. Community coalitions to control chronic disease: Allies Against Asthma as a model and case study. Health Promot Pract. 2006 Apr;7(2 Suppl):14S-22S.

10. Oandasan I, Reeves S. Key elements of interprofessional education. Part 2: Factors, processes and outcomes. J Interprof Care. 2005 May;19 Suppl $1: 39-48$.

11. Steenbergen G, El Ansari W. The power of partnership. Geneva: WHO; 2003.

12. El Ansari W, Oskrochi R, Phillips CJ. One size fits all partnerships? What explains community partnership leadership skills? Health Promot Pract. 2010 Jul;11(4):501-14.

13. Butterfoss FD, Lachance LL, Orians CE. Building allies coalitions: why formation matters. Health Promot Pract. 2006 Apr;7(2 Suppl):23S-33S.

14. Butterfoss FD, Gilmore LA, Krieger JW, Lachance LL, Lara M, Meurer JR, et al. From formation to action: how Allies Against Asthma coalitions are getting the job done. Health Promot Pract. 2006;7(2 Suppl):34S-43S.

15. El Ansari W. Community development and professional education in South Africa. In: Mitchell S, editor. Effective educational partnerships: experts, advocates, and scouts. Westport: Praeger; 2002. 
16. Laraia BA, Dodds J, Eng E. A framework for assessing the effectiveness of antihunger advocacy organizations. Health Educ Behav. 2003 Dec;30(6):756-70.

17. Zakocs RC, Edwards EM. What explains community coalition effectiveness?: a review of the literature. Am J Prev Med. 2006 Apr;30(4):351-61.

18. Kumpfer KL, Turner C, Hopkins R, Librett J. Leadership and team effectiveness in community coalitions for the prevention of alcohol and other drug abuse. Health Educ Res. 1993;8(3):359-74.

19. El Ansari W. An Introduction to the structural and operational underpinnings of partnership work. In: Goede H, El Ansari W, editors. Partnership work: the health service-community interface for the prevention, care and treatment of HIV/AIDS : report of a WHO consultation. Geneva: WHO; 2003. p. 10.

20. Granner ML, Sharpe PA. Evaluating community coalition characteristics and functioning: a summary of measurement tools. Health Educ Res. 2004 Oct;19(5):514-32.

21. Goede H, El Ansari W, editors. Partnership work: the health servicecommunity interface for the prevention, care and treatment of HIV/AIDS: report of a WHO consultation. Geneva: WHO; 2003.

22. Prestby JE, Wandersman A. An empirical exploration of a framework of organisational viability: maintaining block organisations. J Appl Behav Sci.1985;21(3):287-305.

23. Wandersman A, Florin P, Friedmann R, Meier R. Who participates, who does not, and why? An analysis of voluntary neighborhood organizations in the United States and Israel. Sociol Forum. 1987;2(3):534-55.

24. Giamartino GA, Wandersman A. Organisational climate correlates of viable urban block organisations. Am J Community Psychol. 1983;11(5):529-41.

25. Lazarus J. Towards a model for transforming health personnel education, research and service: the South African experience. Health Syst Trust [Internet]. 1996 May [cited 2012 Apr 19];(16). Available from: http:// www.hst.org.za/uploads/files/update16.pdf.

26. Lumague M, Morgan A, Mak D, Hanna M, Kwong J, Cameron C, et al. Interprofessional education: the student perspective. J Interprof Care. 2006 Jun;20(3):246-53.

27. Goodrow B, Olive KE, Behringer B, Kelley MJ, Bennard B, Grover $\mathrm{S}$, et al. The Community partnerships experience: a report of institutional transition at East Tennessee State University. Acad Med. 2001 Feb;76(2):134-41.

28. El Ansari W. Joint working for health and social outcomes: the partnership-leadership mantra. Int J Leadersh Public Serv. 2009;5(1):29-36.

29. Sheaff R, Schofield J, Mannion R, Dowling B, Marshall M, Mcnally $R$. Organisational factors and performance: a review of the literature. London: The National Co-ordinating Centre for NHS Service Delivery and Organisation R\&D; 2004.

30. Huxham C, Vangen S. Ambiguity, complexity and dynamics in the membership of collaboration. Hum Relat. 2000;53(6):771-806.

31. Vangen S, Huxham C. Enacting leadership for collaborative advantage: dilemmas of ideology and pragmatism in the activities of partnership managers. Brit J Manage. 2003;14(s1):S61-S76.

32. Kreuter MW, Lezin NA, Young LA. Evaluating community-based collaborative mechanisms: implications for practitioners. Health Promot Pract. 2000;1(1):49-63.

33. Butterfoss FD. The coalition technical assistance and training framework: helping community coalitions help themselves. Health Promot Pract. 2004 Apr;5(2):118-26.

34. Robinson KL, Driedger MS, Elliott SJ, Eyles J. Understanding facilitators of and barriers to health promotion practice. Health Promot Pract. 2006 Oct;7(4):467-76

35. Rogers T, Howaerd-Pitney B, Fieghery EC, Altman DG, Endres JM, Roeseler AG. Characteristics and participant perceptions of tobacco control coalitions in California. Health Educ Res. 1993;8(3):345-57.
36. Gottlieb NH, Brink SG, Gingiss PL. Correlates of coalition effectiveness: the Smoke Free Class of 2000 Program. Health Educ Res. 1993 Sep;8(3):375-84.

37. Minnesota Department of Health. A self-assessment form for use by a community health committee (Community Health Services Administration Work Group Draft Interim Report). Minneapolis: Department of Health; 1990

38. WK Kellogg Foundation. Health profession education and community partnership study. Lansing: Michigan State University, Survey Research Division of the Institute for Public Policy and Social Research; 1994.

39. Prestby JE, Wandersman A, Florin P, Rich R, Chavis D. Benefits, costs, incentive management and participation in voluntary organisations: a means to understanding and promoting empowerment. Am J Community Psychol. 1990;18(1):117-49.

40. Zapka JG, Marrocco GR, Lewis B, McCusker J, Sullivan J, McCarthy J, et al. Inter-organizational responses to AIDS: a case study of the Worcester AIDS Consortium. Health Educ Res. 1992 Mar;7(1):31-46.

41. Strauss A, Corbin J. Grounded theory methodology: an overview. In: Denzin NK, Lincoln YS, editors. Handbook of qualitative research. Thousand Oaks, CA: Sage; 1994. p. 273-85.

42. Vangen S, Huxham C. Nurturing collaborative relations: building trust in inter-organizational collaboration. J Appl Behav Sci. 2003;39(1):5-31.

43. Bowling A. Research methods in health: investigating health and health services/Ann Bowling. Buckingham, UK: Open University Press; 1997.

44. El Ansari W, Weiss ES. Quality of research on community partnerships: developing the evidence base. Health Educ Res. 2006 Apr;21(2):175-80.

45. Zakocs RC, Guckenburg S. What coalition factors foster community capacity? Lessons learned from the Fighting Back Initiative. Health Educ Behav. 2007 Apr;34(2):354-75. Erratum in: Health Educ Behav. 2007 Jun;34(3):551.

46. Buys N, Bursnall S. Establishing university - community partnerships: processes and benefits. J Higher Educ Pol Manage. 2007;29(1):73-86.

47. Alexander MP, Zakocs RC, Earp JAL, French E. Community coalition project directors: what makes them effective leaders? J Public Health Manag Pract. 2006 Mar-Apr;12(2):201-9.

48. Chrislip DD, Larson CE. Collaborative leadership: how citizens and civic leaders can make a difference. American Leadership Forum Book. San Francisco: Jossey-Bass, American Leadership Forum Series; 1994.

49. El Ansari W, Phillips CJ, Zwi AB. Narrowing the gap between academic professional wisdom and community lay knowledge: perceptions from partnerships. Public Health. 2002 May;116(3):151-9.

50. Bolden R, Gosling J. Leadership competencies: time to change the tune? Leadership. 2006;2(2):147-63.

51. Richter AW, West MA, Van Dick R, Dawson JF. Boundary spanners' identification, intergroup contact, and effective intergroup relations. Acad Manage J. 2006;49(6):1252-69.

52. Eden C, Huxham C. The negotiation of purpose in multi-organizational collaborative groups. J Manage Stud. 2001;38(3):373-91.

53. Hosking DM, Morley IE. A Social psychology of organizing: people, processes and contexts. New York: Harvester/Wheatsheaf; 1991.

54. Kegler MC, Norton BL, Aronson RE. Strengthening community leadership: evaluation findings from the California Healthy Cities and Communities Program. Health Promot Pract. 2008 Apr;9(2):170-9. 